Faculdade de Ciências Econômicas UFRGS

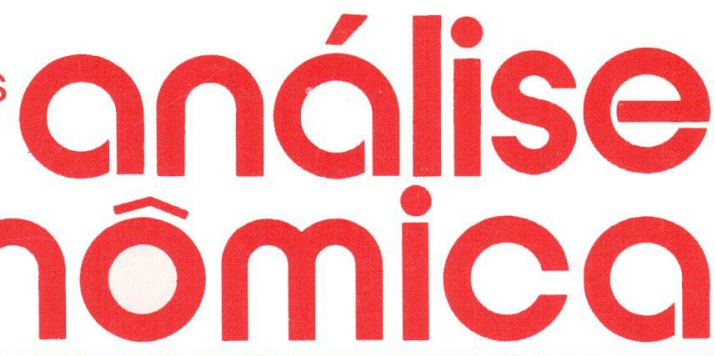

- teoria do balanço de PAGAMENTOS Joáo Luis Tenreiro Barroso

- a IMPORTÂncIa das teorias DE SALÁRIO PARA AS TEORIAS DE INFLAÇÃO Lúcia Maria Góes Moutinho

- os ciclos da economia BRASILEIRA

Vera Beatriz da Silva Oliveira

- SUBSÍDIOS DE PREÇOS AO TRIGO NO BRASIL

Vera Martins da Silva

- A EFICIÊnCIA dA AGRICULtURA GAÚCHA

Juvir Luiz Mattuella

- A economia Regional no BRASIL

Paulo Roberto Haddad

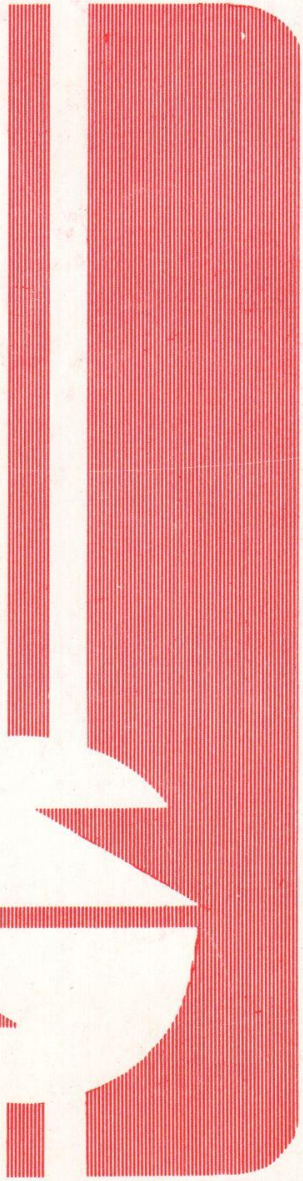


UNIVERSIDADE FEDERAL DO RIO GRANDE DO SUL

Reitor: Prof. Gerhard Jacob

FACULDADE DE CIÊNCIAS ECONÔMICAS

Diretor. Prof. Walter Meucci Nique

CENTRO DE ESTUDOS E PESQUISAS ECONÔMICAS

Diretor: Prof. Reinaldo Ignacio Adams

DEPARTAMENTO DE CIÊNCIAS ECONÔMICAS

Chefe: Profa Oțtlia Beatriz Kroeff Carrion

CURSO DE PÓS-GRADUAÇĀO EM ECONOMIA

Coordenador: Prof. Roberto Camps Moraes

CURSO DE PÓS-GRADUAÇĀO EM ECONOMIA RURAL

Coordenador: Prof. Aray Miguel Feldens

CONSELHO EDITORIAL:

Achyles Barcelos da Costa, Aray Miguel Feldens, Atos Freitas Grawunder, Carlos Augusto Crusius, Ernani Hickmann, João Rogério Sanson, Juvir Luiz Mattuella, Maria Imilda da Costa e Silva, Nali de Jesus de Souza, Nuno Renan Lopes de Figueiredo Pinto, Otília Beatriz Kroeff Carrion, Otto Guilherme Konzen, Paulo Alexandre Spohr, Pedro Cezar Dutra Fonseca, Reinaldo Ignacio Adams, Roberto Camps Moraes, Valter José Stülp, Yeda Rorato Crusius, Edgar Augusto Lanzer (UFSC) e Humberto Vendelino Richeter (UnB)

COMISSĀO EDITORIAL: Atos Freitas Grawunder; Pedro Cezar Dutra Fonseca, Reinaldo Ignacio Adams e Roberto Camps Moraes.

EDITOR: Nali de Jesus de Souza

SECRETARIA: Francisco Carlos Becco dos Santos, Maria Ivone de Mello (normalizaçāo), Vanete Ricacheski (revisão de textos), Wagner Nunes e Zélide Bregaida.

FUNDADOR: Prof. Antônio Carlos Rosa

A Revista ANÁLISE ECONÔMICA publica dois números anuais nos meses de março e novembro. O preço da assinatura, para 1990, é de 7,0 BTNs (o número avulso custa 4 BTNs), a ser pago através de cheque nominal em nome da "Faculdade de Ciências Econômicas/ UFRGS". Aceita-se permuta com revistas congêneres. Aceitam-se, também, livros para elaboração de resenhas ou recensōes.

Toda correspondência, material para publicação, assinaturas e permutas devem ser dirigidos ao seguinte destinatário:

PROF. NALI DE JESUS DE SOUZA

Revista Análise Econômica

Av. João Pessoa, 52 - sala 28

90.040 - PORTO ALEGRE (RS) - BRASIL

Telefone: 25-5844 ramal 34 


\section{A ECONOMIA REGIONAL NO BRASIL: VELHAS DIMENSÕES, NOVAS PERSPECTIVAS*}

\section{Paulo Roberto Haddad *}

Neste texto, pretendemos desenvolver algumas idéias visando a provocar um debate durante o XVI Encontro da ANPEC sobre as perspectivas do ensino e da pesquisa em Economia Regional no Brasil, neste limiar do século XXI. Como, tradicionalmente, a principal questão política que vem motivando o interesse pela Economia Regional em nosso Paĺs, ao longo das três últimas décadas, é a dos desequilibrios regionais de desenvolvimento, cabe uma primeira indagação sobre as possibilidades de se observar a reversão da polarização durante um novo ciclo de expansão da economia brasileira com chances de se realizar ainda no início da década de noventa. A segunda indagação se relaciona com a tentativa de se explicar o crescente desinteresse pelos temas de ensino e de pesquisa da Economia Regional provocado por uma possível especialização excessiva deste ramo científico em torno de temas de abrangência restrita para o interesse público e de limitado escopo em termos intelectuais. Finalmente, uma terceira e última indagação: se o paradigma analítico da Economia Regional que vem dando suporte à formulação de políticas públicas de incidência espacial não seria também responsável pelo freqüente insucesso destas políticas, derivando-se daí um desinteresse pelos seus temas de ensino e de investigação científica?

Como este texto é de caráter provocativo, espera-se que outras questōes sejam levantadas durante os debates e que, até mesmo, sejam contestadas as abordagens nele apresentadas.

* Trabalho apresentado no $16^{\circ}$ Encontro de Economia da ANPEC, realizado em Belo Horizonte, em dezembro de 1988.

** Professor da FACE/CEDEPLAR - UFMG.

ANÁLISE ECONŌMICA

\begin{tabular}{l|l|l} 
ANO 7 & №11 & MARÇO/89
\end{tabular}

p.131-148 


\section{REVERSÃO DA POLARIZAÇÃO?}

Em geral; os especialistas que têm escrito sobre a questão da evolução da distribuição espacial das atividades econômicas e da população no Brasil registram duas tendências marcantes: a) a partir da maior participação das grandes régióes menos desenvolvidas (Norte, Nordeste, Centro-Sul) no PIB do País e no valor de transformação industrial, entre 1970 e 1980, apontam o surgimento de um incipiente mas decisivo processo de desconcentração econômica e de despolarização da indústria nacional; b) simultaneamente a um sensivel decréscimo no ritmo de crescimento da população brasileira, esperam uma urbanização mais acelerada nos próximos anos, enquanto a intensidade e a direção dos fluxos migratórios ficarão na dependência do aprofundamento do processo de modernização agrícola em áreas onde prevalece a pequena produção familiar, da distribuição das atividades econômicas entre as regióes e sua capacidade de gerar oportunidades intervenientes de emprego local, etc.

Sem nos determos na discussão das questōes demográficas que serão tratadas em sessão específica do Encontro, vamos admitir, para fins de análise, que estas tendências de fato se manifestaram na última década, embora algum esforço de reflexão deveria ser feito para se avaliar o que ocorreria com a distribuição do PIB e do VTI, quando passássemos do conceito de "interno ou geográfico" para o de "residentes ou regional" nos procedimentos de cálculo destes agregados econômicos. Ora, para estudos comparativos entre níveis de desenvolvimento das diferentes regiōes de um país a partir de indicadores sintéticos, o mais significativo é o produto (ou renda) regional que se distancia do produto interno pela diferença dada pela "renda líquida enviada para o exterior".

Como se sabe, as regióes de um país são economias abertas onde as transações externas são, em geral, muito mais importantes relativamente do que as transações com o exterior de uma economia nacional. Entretanto, como a nação é uma unidade político-cultural que se diferencia para fins de política econômica do resto do mundo, os agentes econômicos tendem a distinguir, no seu sistema de contabilidade, aquelas transações com produtos e fatores que são internas ao país daquelas transaçōes que são internacionais; como não é comum, entre esses mesmos agentes, a discriminação das transaçōes entre partes na mesma região e transaçōes entre partes em outras regiōes, 
fica praticamente impossível o cálculo dos "rendimentos líquidos enviados para o exterior" para se chegar à renda regional.

Esta distorção do PIB (assim como do VTI) como indicador para se analisar a tendência da distribuição espacial das atividades econômicas é particularmente grave no caso brasileiro onde o crescimento do produto das regiōes periféricas ocorreu durante a década de setenta, e vem ocorrendo agora, como movimentos incentivados de expansão no espaço das diferentes formas de capital de empresas sediadas nas áreas mais desenvolvidas do Brasil ou em outros paises; quando a estes movimentos se somam os rendimentos de outros fatores e serviços que "vazam" das regiōes periféricas em direção às áreas centrais, não é difícil imaginar as profundas alterações que poderiam ocorrer na distribuição espacial do PIB pelo fato de se trabalhar com o produto interno e não com a renda regional, a qual reflete de maneira mais aproximada o nível de bem-estar da população. ${ }^{1}$

Para identificar que tipo de padrão dos desequilíbrios regionais de desenvolvimento poderá prevalecer no fim deste século e início do século XXI, temos que considerar, além das tendências observadas no passado recente, as condicionalidades que irão restringir o crescimento das regiōes periféricas do País. Entre estas condicionalidades podemos destacar: a crise fiscal e financeira do Estado e o comportamento que a sociedade pretende atribuir à questão ecológica, pois, de um lado, a primeira condicionalidade delimita a capacidade que terá o poder central para apoiar o desenvolvimento daquelas regiōes e, de outro, a segunda condicionalidade estabelece os limites do crescimento econômico a partir da maior ou menor velocidade e intensidade de transformação dos subsistemas ecológicos regionais. É evidente que a importância relativa destas condicionalidades dentro da questão regio-

1 Um exercicio pode ser ilustrativo para caracterizar o argumento: a) tomemos o produto interno bruto a custo de fatores mais imputação dos serviços de intermediaçăo financeira segundo Grandes Regíbes, englobando, de um lado, o bloco das regióes SUDESTE/SUL $\theta$, de outro, o bloco das regiöes NORTE/NORDESTE/CENTROESTE (a periferia tradicional e a periferia dinâmica); b) calculemos a participação relativa de cada bloco de regióes no PIB, em 1970 e 1980; c) façamos o mesmo cálculo, transferindo para o bloco mais desenvolvido parcela da renda gerada no bloco menos desenvolvido em 1980, sob a forma de "rendimentos liquidos enviados para o exterior". Os resultados mostram que seria suficiente a transteréncia de menos de $15 \%$ do PIB, em termos incrementais, para que se descaracterizasse uma inequivoca desconcentração espacial do desenvolvimento. Ora, este é um valor muito pequeno quando se observa a experiência' internacional de situaçб̄es semelhantes à do Brasil. As estatisticas do PIB por Grandes Regióes foram retiradas do livro publicado pelo IBGE (1987, tab. 4.13). 
nal dependerá das características econômicas e políticas da trajetória mais provável para o crescimento econômico e social do Brasil até o século XXI, cujo exame mais detalhado escapa aos objetivos deste texto. ${ }^{2}$

Como é conhecido, ao longo da década passada, era comum os três níveis do Governo (Federal, Estaduais e Municipais) disporem de recursos financeiros da ordem de dez a quinze bilhões de dólares de poupança anual em seus orçamentos fiscais para financiar investimentos de infra-estrutura da economia brasileira em suas diversas regiōes. Esta poupança, concentrada principalmente nos orçamentos do Governo Federal e de alguns Governos Estaduais e Municipais das áreas desenvolvidas do País, dava ao processo de planejamento regional um significativo grau de liberdade para a definição de programas e de projetos a serem financiados e implementados, particularmente atraves de transferências negociadas para as regióes periféricas.

Infelizmente, esta fonte de financiamento dos gastos de investimento declinou sensivelmente na atual década, a ponto de se estimar que poderia ser nula ou negativa a poupança em conta-corrente do Governo em 1988, se não fossem tomadas medidas de natureza estabilizadora. Os principais tatores são conhecidos: a receita tributária bruta, que representava, em 1970, cerca de vinte e seis por cento do PIB, vem caindo, tendo ficado pouco acima de vinte por cento nos últimos anos; os pagamentos dos encargos sobre a dívida pública interna (exclusive correção monetária) que, em 1980, representavam apenas $0,7 \%$ do $\mathrm{PIB}$, têm-se situado em torno de quase $4 \%$; os diversos tipos de subsídios que, em 1970 , eram de $0,8 \%$ do PIB chegaram a mais de $2 \%$ nos anos recentes. Assim, a carga tributária líquida, que equivale à arrecadação de impostos menos os subsídios e as transferências, também vem sofrendo grande deterioração: tendo atingido a $17,4 \%$ do PIB em 1970, está estimada atualmente em apenas $10 \%$, valor igual à despesa corrente do Governo com salários e encargos $(7,0 \%$ do PIB) e compras de bens e serviços ( $3,0 \%$ do PIB), sem sobra de recursos próprios, pois, para o autofinanciamento de investimentos públicos. Esta situação é particularmente mais crítica no caso dos Governos Estaduais das áreas menos desenvolvidas uma vez que os recentes indicadores de desempenho financeiro demonstram grave dete-

2 Entre os cenários alternativos para a economia brasileira e a economia mundial, ver Porto (1988) e Fritsch \& Modiano (1987). 
rioração na sua capacidade de financiar autonomamente investimentos de escala mais expressiva.

Dificuldades semelhantes serảo encontradas para se negociar e atrair recursos dos orçamentos das empresas estatais controladas pelo Governo Federal que se destinariam a financiar programas e projetos nas regiỏes menos desenvolvidas, visando a melhorar sua posição relativa no conjunto do País. Registra-se que, em meados da década de setenta, estas empresas chegaram a gerar uma poupança equivalente a $20 \%$ do total do setor privado, a qual financiava quase dois terços dos seus investimentos, muito dos quais realizados naqueles regiōes, tendo em vista critérios de rentabilidade social dos projetos de desenvolvimento. Atualmente, a geração de poupança própria corrente das empresas estatais está conseguindo financiar bem menos da metade de seus investimentos, mesmo porque estes têm sido drasticamente reduzidos para se acomodar a esta disponibilidade de poupança; entre outros motivos, para explicar esta deterioração, podemos citar: a) para reduzir o ritmo inflacionário, o poder público, em vários anos desde 1974, vem controlando os preços e as tarifas dos bens e serviços que geram a receita operacional das empresas estatais, reduzindo sua capacidade de autofinanciamento e de alavancagem de recursos nos mercados financeiros interno e externo; b) estas empresas foram utilizadas como instrumento de captação de recursos externos com o objetivo de avaliar as pressões do balanço de pagamentos a partir dos últimos anos da década de setenta, com reflexos negativos em termos de seus encargos financeiros e de seus índices de rentabilidade; como conseqüência, na estrutura de dispêndios das empresas do setor produtivo estatal, houve um aumento explosivo dos seus custos financeiros que, praticamente, anulou o esforço de contenção das despesas operacionais, entre as quais as de pessoal e as de encargos (Werneck, 1987).

Assim, é reduzida a flexibilidade que estas empresas dispõem para alocar recursos escassos em programas e projetos de desenvolvimento regional; como o Governo Federal e os Governos Estaduais não têm condições de promover transferências significativas dos orçamentos fiscais para os programas de investimentos destas empresas (como no passado), a sua intervenção direta nas economias periféricas através delas tende a ser mais e mais restritiva.

Nesta mesma linha, menciona-se a segunda condicionalidade a partir das contradições que têm ocorrido entre as intenções apologéti- 
cas dos planejadores em realizar o processo de desenvolvimento "sem devastação dos recursos naturais do Paĺs" e a estratégia geral que tem prevalecido no modelo de desenvolvimento econômico do País, em anos recentes. Para esse propósito, é necessário destacar os conflitos que políticas macroeconômicas de estabilização e de crescimento, esboçadas para atender à solução de problemas de interesse nacional, poderão ter com o objetivo de uma exploração racional dos recursos naturais das diferentes regiōes e de uma preservação dos seus ecossistemas.

Pode-se reportar, por exemplo, às políticas recentes do Governo Federal na Amazônia, as quais incluíram como elementos principais um ambicioso programa de investimentos em infra-estrutura, combinado com programas de colonização ao longo das principais rotas, investimentos na obtenção de informaçōes sobre recursos naturais para reduzir as incertezas sobre o potencial de desenvolvimento da regiāo e diferentes formas de incentivos fiscais para atrair investimentos privados para os setores de agricultura, pecuária, silvicultura, mineração, etc.

Embora a implementação dessas políticas ainda tenha seus desdobramentos futuros, estudos que as têm avaliado apontam que, se, por um lado, o recente desenvolvimento da infra-estrutura sócio-econômica da Amazônia tem diminuído o seu isolamento em relação ao resto do Pais e permitido descortinar novas alternativas de investimento, por outro, a estratégia de ocupação acelerada do espaço e de exploraçāo intensiva dos recursos naturais através de grandes projetos de mineraçāo e agropecuária tem intensificado, de maneira brutal, e destruição da fauna e da flora na região.

A intenção dos planejadores em estabelecer uma taxa ótima de utilização dos recursos naturais do País, segundo critérios de bem-estar social, envolveria uma discussāo mais crítica sobre as condiçōes de apropriação desses recursos, as taxas sociais de desconto a serem aplicadas na avaliação dos projetos de exploração, os ritmos adequados de utilização dos recursos em função da poluição ambiental e dos interesses das geraçōes futuras, etc. Uma implicação mais ampla dessa discussão poderá conduzir-nos à própria redefinição do processo de desenvolvimento em termos ecológicos. Uma implicação mais restrita exigiria apenas que o Brasil tivesse uma política de recursos naturais com objetivos específicos que nāo fossem somente reflexos de inte- 
resses ligados às metas de crescimento global e setorial da economia, as quais têm tido uma posição dominante na solução de situaçōes conflitivas. Assim, com as dificuldades surgidas no balanço de pagamentos, é provável que o País continue a explorar, numa taxa indesejável, o seu potencial de recursos naturais renováveis e não-renováveis, como forma de contribuir para o crescimento acelerado de suas exportações, que se transformaram numa variável crítica dentro do atual contexto.

Mas, ao lado de tendências e de condicionalidades, constatamos também a existência de eventos portadores de mudanças que irão afetar a natureza da questão regional até o século XXI; entre os quais se destacam:

1 - o novo sistema tributário aprovado pela Constituinte tem, entre seus objetivos fundamentais, a descentralização e o fortalecimento da autonomia dos Estados e Municípios, assim como a atenuação dos desequilíbrios regionais de desenvolvimento; é de se esperar, pois, pelas mudanças já definidas pela Constituinte, que as áreas periféricas venham a dispor de mais recursos fiscais para os programas e projetos de seu interesse, particularmente quando se destaca a norma constitucional que prevê a manutenção e ampliação dos pagamentos de royalties sobre a exploração e a exportação, pelas Unidades da Federação, de petróleo, minérios estratégicos e energia; (Resende, 1987)

2 - a revolução científica e tecnológica que amadurece e difunde, com velocidade relativamente intensa, novos produtos e processos, está provocando transformaçōes sociais e econômicas fundamentais as quais irão certamente influenciar os padrōes de desenvolvimento regional através dos rebatimentos espaciais dos investimentos na microeletrônica, na biotecnologia, nos novos materiais e nas novas fontes energéticas, os quais deverão ocorrer de forma mais transparente a partir de um novo ciclo de expansão da economia brasileira;

3 - a nova divisão internacional do trabalho, intensificada a partir da segunda metade da década passada, abre a oportunidade para que os novos paises industrializados, como o Brasil, possam aproveitar suaș vantagens comparativas para expandir a produção de bens de consumo e insumos bási- 
cos em condições bastante competitivas; é evidente que es" ta nova forma de inserção do País no cenário internacional irá provocar reestruturações na distribuição espacial das atividades produtivas entre nossas regiões.

Tendências identificadas, condicionalidades configuradas e eventos portadores de mudanças delimitados, cabe-nos projetar as perspectivas dos desequilibrios regionais de desenvolvimento no Brasil até o início do século XXI, o que significa indagar se, após cinco décadas de marcante concentração espacial desde que se intensificou a industrialização brasileira a partir da crise de 29 , não estaríamos no limiar da "reversão da polarização", situação definida por Richardson como o ponto de mudança a partir do qual as tendências de polarização espacial na economia nacional dão lugar a um processo de dispersão espacial para fora da região central, em direção a outras regiōes do sistema. ${ }^{3}$ Infelizmente, temos que abrir um conjunto de argumentos os quais mostram as possibilidades de ocorrer até o século XXI um processo de não-reversão da polarização espacial, iniciada na década passada, contrariamente ao que, de forma intuitiva, estamos todos esperando. Estes argumentos serão apresentados de maneira enfática, pois as tendências que se delineiam, a partir deles, podem ser preventivamente contrapostas por um número limitado e factivel de políticas de desenvolvimento regional eficazes em termos de se atenuar um possível processo de reconcentração espacial ao longo dos próximos anos:

1 - no nível de desenvolvimento a que chegou o Brasil, com uma estrutura produtiva amplamente diversificada e complexa, é de se esperar que surjam resistências à alteração do padrão de distribuição espacial das atividades produtivas por causa da imobilização de capital fixo nas áreas desenvolvidas; esta influência concentracionista do espaço construído será tanto maior quanto menor for a capacidade do sistema para financiar novos investimentos;

2 - quando do início de um novo ciclo de expansão da economia brasileira, provavelmente na primeira metade da próxima década, aumentam-se os volumes de recursos públicos

3 Para discutir a questão da reversăo da polarização, utilizamos, como referência bibliográfica, os textos de Azzoni (1986), Diniz (1987), Alves (1984), Alves (1986), Haddad (1986) e Richardson (1980). 
(para o crescimento da oferta de infra-estrutura) e privados (para ampliação e implantação de unidades produtivas) capazes de quebrar a resistência inercial do espaço construído à dispersão das atividades econômicas; este ciclo de expansão cria, pois, as condições necessárias para uma situação de reversão de polarização, mas não as condições suficientes, pois não há em processo uma tendência inequivoca que as regiões periféricas (tradicionais ou dinâmicas) venham a crescer em ritmo mais acelerado do que as regiōes mais desenvolvidas;

3 - as incertezas em relação às condiçōes suficientes nascem das seguintes preocupaçōes: a) a expansão das atividades produtivas para atender a demanda agregada de alimentos, fibras e produtos energéticos as quais se orientam locacionalmente para a base de recursos naturais pode não se implantar preferencialmente na fronteira externa, situada, principalmente, na Regiāo Amażônica (por causa dos seus elevados custos ecológicos, dos graves problemas na sua estruturação fundiária, da precária acessibilidade dos mercados e de investimentos necessários para colocar-se mais terra em produção), mas sim na fronteira interna ("a parte situada dentro da área permanentemente conquistada pela agricultura, possuindo condições agronômicas e legais de ser agricultada e que não é explorada, a não ser em atividades extrativas") de regiōes que já dispõem de infra-estrutura e de adequada acessibilidade aos mercados consumidores, o que aumenta as possibilidades locacionais das áreas mais desenvolvidas do País para a atração daquelas atividades; b) embora sejam nítidas as tendências à desconcentração espacial relativa da produção mineral brasileira nas próximas duas décadas, há que se registrar de um lado, uma perspectiva de solução pouco favorável para a atual crise da indústria mineral internacional e, de outro, a limitada capacidade desta atividade em germinar e dispersar efeitos de crescimento nas próprias áreas periféricas onde se implanta; c) existem evidências de que os centros urbanos localizados dentro do campo aglomerativo da grande regiāo industrial brasileira (nos eixos rodoviários e dentro dos anéis de influência que saem das grandes metrópoles desta região) 
apresentam vantagens locacionais para a atração de novos projetos de investimentos industriais em maior intensidade do que as principais cidades das regiões periféricas do País, pois podem usufruir das chamadas economias de urbanização e de aglomeração disponíveis nos centros metropolitanos sem ter de incorrer nos crescentes custos locacionais a que estes centros estão presos; d) embora tenha se investigado relativamente pouco sobre o padrão locacional dos produtos e processos que estão emergindo do novo ciclo mundial de inovações tecnológicas, não há evidência de que, com a retomada da expansão econômica do País, eles venham a contribuir para a reversão da polarização, pois alguns deles (os novos metais, por exemplo) tenderão a se localizar junto ao parque industrial já instalado, enquanto outros, apesar de seu caráter "foot-loose" (a microeletrônica, por exemplo), terão uma forte preferência pela acessibilidade aos mercados concentrados e ao ambiente metropolitano; registra-se, contudo, que a produção de insumos energéticos alternativos a partir da biomassa conta a favor da dispersão espacial das atividades; e) o surto de crescimento que poderia ocorrer na periferia dinâmica (particularmente, na Amazônia) a partir do dinamismo de uma base de exportação de insumos mínero-metalúrgicos viabilizada pela reestruturação da divisão internacional do trabalho esbarra, do lado do poder público, na limitada capacidade de financiamento da infra-estrutura de suporte às atividades produtivas e nos efeitos desarticuladores dos ecossistemas regionais que a implantação destas atividades poderá provocar;

4 - como as políticas macroeconômicas e setoriais não são neutras em termos de seus impactos espaciais, acredita-se que os seus efeitos regionais implícitos possam predominar sobre os efeitos das políticas explícitas de crescimento regional, agravando, eventualmente, a questão dos desequilfbrios de desenvolvimento no espaço, a não ser que venha a prevalecer, no cenário nacional, uma aliança de forças politicas dentro da qual o poder público esteja efetivamente comprometido com políticas distributivas e mobilize açōes compensatórias em benefício das regiões afetadas pelos 
efeitos perversos das políticas macroeconômicas ou setoriais.

\section{UM RAMO CIENTÍFICO COM ESPECIALIZAÇÃO EXCESSIVA E DESINTERESSANTE?}

Já se disse que o especialista é aquele que conhece cada vez mais de cada vez menos. Neste sentido, os economistas regionais correm o risco de querer aprofundar um conhecimento especializado sobre assuntos de relevância social duvidosa na medida em que deslocam as suas atividades profissionais das principais questōes que afetam o processo de desenvolvimento do País. Uma especialização excessiva conduz ao esvaziamento de interesse pelos temas do ensino e da pesquisa da Economia Regional o qual será tanto maior quanto mais a dimensão espacial for tratada como campo analítico específico e estiver desligada dos enfoques macroeconômicos e microeconômicos de investigação dos problemas de crescimento, de estabilidade e de distribuição do sistema econômico. Uma ilustração sobre as possibilidades de reintegração da Economia Regional às principais controvérsias atuais da economia brasileira (e, portanto, de transformação do economista regional em um profissional que tem uma visão mais abrangente sobre os mesmos problemas que se analisam nos estudos convencionais de macroeconomia e de microeconomia) pode ser dada pelo esforço de pesquisa que vem sendo desenvolvido na análise do impacto espacial das políticas macroeconômicas de estabilizaçāo e das políticas setoriais de crescimento (agrícola, industrial, etc.): Em todos os estilos de concepção e de implementação destas políticas, adotados em diversos países da América Latina, incluindo as recentes experiências de estabilização a partir de choques heterodoxos, não há, em geral, nenhuma preocupação dos formuladores dessas polfiticas em diferenciar os instrumentos, as normas e as regulamentaçōes dos processos de reajustamento interno e externo, visando a influenciar os fenômenos de interação inter-regional, principalmente os que afetam os niveis de renda e de emprego de regiōes especificas. Os instrumentos das políticas macroeconômicas e setoriais concebem as economias nacionais de maneira unipuntual, sendo aplicados uniformemente em torno de alguma intervenção governamental que afete a mobilidade espacial de fatores de produção, como, por exemplo, as taxas de juro 
mais reduzidas para o crédito rural em áreas deprimidas numa política de estabilização ou a criação de zonas especiais de exportaçōes numa política industrial. Entretanto, a experiência histórica de diversos países vem demonstrando o caráter de não-neutralidade dos efeitos regionais das políticas macroeconômicas e também das políticas setoriais. Observa-se que, em geral, estas políticas pretendem ser "a-espaciais", no sentido de que são construidas "a partir de valores médios de distribuiçōes com variança mínima", na expectativa de que seus efeitos possam ser homogêneos em diferentes regiōes. Na realidade, quando aplicadas em espaços econômicos e sociais heterogêneos sob aspectos fundamentais em termos de estrutura e dinâmica de crescimento (como é o caso brasileiro), conduzem a impactos diferenciais sobre as regiōes. Donde se conclui que, ao serem constatadas na implementação destas políticas conseqüências não previstas em sua concepção, comprova-se que esta concepção carece da amplitude necessária para analisar a complexidade da situação que se pretende controlar (Ordoñez, 1985) 4 .

Não é difícil mostrar como as exigências analíticas do esforço de se examinarem as políticas macroeconômicas e setoriais a partir de um enfoque mais abrangente e integrado pela dimensão espacial conduz, necessariamente, a que se reformulem as orientaçōes metodológicas do ensino e da pesquisa da Economia Regional. Como se sabe, as variáveis-instrumentos manipuladas com maior freqüência em diferentes estilos de políticas macroeconômicas e setoriais podem ser definidas também em termos da dimensão de sua área geøgráfica de influência em um país considerado como um sistema multirregional. Algumas variáveis operam os seus impactos sobre a economia nacional concebida como um agregado unipuntual, enquanto outras procuram influenciar os niveis de atividades econômicas em regiões especifieas. Esta definição prevalece, contudo, enquanto considerarmos apenas os efeitos explícitos destas variáveis, pois até quando os instrumentos puramente nacionais (taxa de câmbio nominal, taxa de salários nominais, etc.) são aplicados uniformemente sobre todo o país, o seu impacto sobre o crescimento das regiōes pode ser muito diferente, dependendo

4 Sobre o caráter não-neutro em termos espaciais das polf́ticas macroeconómicas e setoriais ver Boisier (1982, cap. III) e Haddad (1986). Ver também a pesquisa que analisa o padrão temporal de difusáo regional da crise brasileira, na primeira metade da atual década, de Gomes (1985), assim como SUDENE (1984), trabalho que investiga os efeitos de outras poIfitieas macroeconómicas e setoriais no Brasil, em diversos perfodos históricos 
fundamentalmente da estrutura econômica e social de cada uma delas.

Assim, para explicar os impactos diferenciados entre regiōes das políticas macroeconômicas e setoriais, temos que compreender, com profundidade, as características fundamentais destas políticas (o que pressupõe um nivel detalhado de familiaridade com a caixa de ferramentas tradicionais de trabalho dos economistas), assim como as diferenças nas estruturas econômicas regionais as quais devem ser endogeneizadas no processo de análise (o que reforça a necessidade de melhor conhecimento sobre a organização espacial das atividades econômicas e sociais). Vale dizer, o que se pretende é resgatar a tradiçāo clássica da Economia Regional a qual considera a maior parte dos processos convencionais đa análise macroeconômica e da análise microeconômica como casos especiais em que se anulam os efeitos da dimensão espacial em condições coeteris paribus.

\section{PARADIGMA ANALITIICO IRRELEVANTE?}

Em geral, o processo de planejamento regional no Brasil, assim como a formulação e a execução de políticas de desenvolvimento regional, tem se fundamentado em um paradigma analítico denominado "de cima para baixo" ou "centro-periferia". Este paradigma parte do pressuposto de que o crescimento se inicia, de forma espontânea ou programada, a partir de alguns setores dinâmicos e aglomerados geográficos e se difunde, posteriormente, para os demais setores e áreas do País. Segundo este paradigma, as potencialidades de crescimento econômico de uma área periférica (não-localizada no centro desenvolvido do Pais) dependem de se detectarem recursos (em geral, naturais renováveis ou não-renováveis) que esta área disponha para estimular a organização de uma base de exportação, a partir de transferências de capital e de tecnologias, e de investimentos de infra-estrutura, visando a explorar suas vantagens comparativas inter-regionais. ${ }^{5}$

Diversos estudos têm feito ampla avaliação empírica desse paradigma a partir de experiências históricas de desenvolvimento regio-

\footnotetext{
5 A discussão sobre a necessidade de um novo paradigma de desenvolvimento regional pode ser encontrada; entre outros textos, em Stör \& Taylor (1981) e em Haddad (1985). No livro de Stör \& Taylor, ver o nosso artigo sobre o caso brasileiro: "Brazil, Economic Efficiency and the Disintegration of Peripheral Regions".
} 
nal em vários países. Em geral, pôde-se concluir (e o caso brasileiro não é exceçāo) que, quando se toma este paradigma como referência analítica para a formulação e implementação de políticas públicas para a promoçāo do desenvolvimento das áreas periféricas (regiōes de recursos, regiōes deprimidas), estas políticas tendem a forjar estruturas que criam relações inter-regionais de dominação econômica e política. Essas estruturas têm-se constituldo, principalmente, em investimentos públicos maciços na criação de sistemas de transporte e de comunicação naquelas regiōes periféricas do País que apresentam elevado potencial para a instalação de grandes projetos agropecuários e extrativos minerais com o objetivo de gerar, a baixo custo, excedentes exportáveis de matérias-primas e alimentos necessários para dinamizar o processo de industrialização em outras regiões do País ou resolver problemas agudos do balanço de pagamentos.

Não é evidente, quando sé observam os padrōes de desenvolvimento regional do Brasil numa perspectiva histórica, que esses grandes projetos possam garantir às regiōes onde se instalam condiçōes estáveis de desenvolvimento. As exportaçōes de produtos orientados para a exploração de recursos naturais (extrativa mineral ou vegetal, agricultura) constituem uma condição permissiva para o impulso inicial do desenvolvimento das economias regionais. Para que essas exportações possam, efetivamente, promover esse desenvolvimento, é necessário que apresentem elevado grau de dinamismo e acentuada capacidade de transmitir esse dinamismo para outros setores produtivos da região, sem se constitúrem em "enclaves". Em diferentes perlodos da História, encontram-se regiöes cujo crescimento se deu, durante algumas décadas, através da extração ou do cultivo de produtos primários, sem que se criassem as bases de um processo de desenvolvimento duradouro.

Para evitar que as áreas periféricas sejam submetidas a uma dinâmica de dominação interna com suporte em grandes projetos predatórios de sua base de recursos naturais, tem-se sugerido um outro paradigma de desenvolvimento, adequado também para áreas deprimidas que nảo esperam ser beneficiadas, em prazo politicamente tolerável, dos efeitos de transbordamento das estratégias expansionistas "de cima para baixo" como as que vêm sendo tradicionalmente adotadas no contexto brasileiro. A concepção e as bases operacionais desse outro paradigma estão intimamente relacionadas com as condições sócio-culturais, históricas e institucionais especificas de cada região. 
Existem, contudo, alguns elementos que são propostos como componentes essenciais das estratégias de desenvolvimento dentro dessas novas alternativas:

1 - provisão de acesso amplo à terra como principal fator de produção nas áreas rurais;

2 - atribuição de prioridade para projetos que sirvam à satisfação das necessidades básicas da população (alimentos, habitação, serviços sociais), utilizando o máximo possível de recursos regionais;

3 - garantia de maiorr grau relativo de autodeterminação para as áreas rurais e periféricas em relação à utilização e transformação das instituições existentes (ou a criação de novas) para a promoção de seu desenvolvimento em função de seus próprios objetivos;

4 - reestruturação dos sistemas urbanos e de transporte para melhorar a acessibilidade regional às funções urbanas e não apenas a acessibilidade aos mercados externos;

5 - no desenvolvimento de atividades básicas para exportaçōes, prioridade a ser dada nas regiōes periféricas para aqueles projetos que facilitem:

a - o pleno emprego dos recursos naturais e de mão-deobra da região;

b - a aplicação de tecnologias que preservem a utilização intensiva de recursos abundantes na região;

c - a competitividade nos mercados extra-regionais baseada em diferenciação qualitativa de produtos e não apenas em preços e escalas de produção, etc.

É fácil perceber como as controvérsias teóricas e doutrinárias sobre a adequação do paradigma analítico como referencial para se estruturarem políticas e planos de desenvolvimento regional poderão reestimular a formação de um ambiente intelectual bastante propício para se resgatar a relevância dos temas do ensino e da pesquisa da Economia Regional no Brasil.

\section{NO LIMIAR DO SÉCULO XXI. . .}

Durante toda a década de oitenta, o Brasil abandonou a prática do planejamento de médio e longo prazo e se jogou numa seqüência 
de politicas de curto prazo, cuja elaboração e execução se alternavam ao longo dos anos em termos de objetivos e estilos próprios, mas que resultaram numa dinâmica perversa para os objetivos gerais do nosso processo de desenvolvimento econômico e social. Constata-se, a título de ilustração, que, diferentemente da década anterior quando o PIB per capita do País cresceu acumuladamente de $69 \%$, ao longo da atual década este crescimento acumulado pode ser nulo. Neste sentido, a perda de "status" dos temas de ensino e de pesquisa da Economia Regional entra na vala comum do esvaziamento de interesse pelas questōes mais críticas do desenvolvimento nacional (pobreza, meio ambiente, descentralização, etc.), ocorrido em favor dos infindáveis e cansativos debates sobre as alternativas de reajustamento da economia no curto prazo. É reconhecida a sucessão de fracassos das estratégias de reajustamento embutidas nas políticas de estabilização que insistem em manter uma visão de curto prazo dos problemas a serem equacionados, sem oferecer um projeto de médio e longo prazo para o desenvolvimento das economias nacionais, o que significa, tecnicamente, transformar condicionantes (a taxa de inflação, o equilíbrio das contas externas) em objetivos de planejamento. Nāo é correto discutir a política fiscal, política salarial ou a política de comércio internacional apenas sob a dimensão da administração da demanda agregada de curto prażo sem articulação com seus efeitos redistributivos (em termos sociais ou espaciais) e com seus impactos sobre a trajetória de crescimento da economia. Esta articulação é politicamente indispensável a fim de fornecer uma elasticidade de tempo maior para a acomodação do espaço de negociações em torno de interesses divergentes. Estas negociações são necessárias à distribuição dos custos sociais dos reajustamentos de curto prazo (aumento da carga tributária, efeitos da desindexação, eventual redução das oportunidades de emprego e de negócios, etc.), o que precisa ocorrer, lado a lado, com politicas e objetivos alternativos que promovam açōes compensatórias para os diversos grupos no médio e no longo prazo.

Assim, é de se esperar que, no bojo da reformulação do conteúdo e do estilo dus políticas públicas, condição necessária para se estabelecer um novo padrão de desenvolvimento do País neste limiar do século XXI, ressurja um interesse ampliado pelos temas do ensino e pesquisa da Economia Regional. Este interesse será tanto maior quanto maior a evolução do tempo for confirmando as proposiçōes avançadas neste texto: a) de que há possibilidades de ocorrer um processo de 
reconcentração espacial dos frutos do crescimento da economia brasileira quando se iniciar um novo ciclo de sua expansão ao longo da década de noventa; esta reconcentração poderá induzir à mobilização política nas áreas periféricas e um renovado interesse intelectual em torno da questão dos desequilíbrios regionais; b) de que há possibilidades de haver uma preocupação analítica cada vez mais intensa em se contraporem os efeitos explícitos das políticas regionais com os efeitos implícitos sobre o espaço das políticas macroeconômicas e setoriais; esta preocupação poderá estimular novos esforços metodológicos visando a incorporação da dimensão espacial nos processos convencionais da análise macroeconômica e da análise microeconômica; c) de que há possibilidades de haver a formulação conceitual de um novo paradigma de desenvolvimento que sirva de referencial para políticas públicas que tenham por objetivo um novo padrão de crescimento com distribuição e preservação ambiental e não apenas de referencial para racionalizar a formação de estruturas de dominação econômica e política nas relações inter-regionais; esta formulação conceitual poderá incentivar os economistas regionais a direcionar sua energia intelectual para as novas correntes do pensamento que trabalham no sentido de romper as limitadas fronteiras do economicismo tradicional por meio da incorporação das relaçōes sócio-institucionais de poder como elementos endógenos aos seus processos de análise regional.

\section{REFERÊNCIAS BIBLIOGRÁFICAS}

ALVES, Eliseu. O Dilema da Política Agrícola Brasileira: Produtivi * dade ou Expansão da Área Agriculturável. Brasília, EMBRAPA, 1984.

- O Crescimento da Demanda e da Oferta de Produtos Agricolas nos Próximos Dez Anos. Análise e Conjuntura. Belo Horizonte, FJP, v.1, n.1, jan./abr., 1960.

AZZONI, C.R. Indústria e Reversão da Polarização no Brasil. São Paulo, IPE/USP, 1986.

BOISIER, Sérgio. Politica Economica, Organización Local y Desarrollo Regional. Cuadernos del ILPES. Santiago de Chile, n.29, 1982. 
DINIZ, C.C. Capitalismo, Recursos Naturais e Espaço. Campinas, UNICAMP/IE, 1987. (Tese dout. econ.).

FIBGE. Estatísticas Históricas do Brasil. Rio de Janeiro, 1987 (Tab. 4.13).

FRITSCH, Winston \& MODIANO, Eduardo M. A Restrição Externa ao Crescimento Econômico Brasileiro: uma Perspectiva de Longo Prazo. Rio de Janeiro, PUC, 1987.

GOMES, G.M.; OSÓRIO, C. \& IRMĀO, J.F. Recessão e Desemprego nas Regióes Brasileiras. Recife, PIMES, UFPE, 1985.

HADDAD, Paulo Roberto. Dimensões do Planejamento Estadual no Brasil. Análise de Experiências. Rio de Janeiro, IPEA/PNPE, 1985.

—. Política de Estabilização Econômica: a Dimensão Regional. Pensamiento Iberoamericano. Madrid, n.10, 1986.

ORDOÑEZ, F. El Desarrollo Regional en el Contexto de los Procesos de Ajuste Macroeconomicos. Washington, OEA, Departamento de Desarrollo Regional, 1985.

PORTO, Cláudio et alii. Cenários Energéticos Para a Amazônia. ELETRONORTE, 1988.

REZENDE, F. \& AFONSO, J.R.R. A Reforma Fiscal no Processo de Elaboração da Nova Constituição. Rio de Janeiro, IPEA, 1987. (Texto Para Discussão, n.121).

RICHARDSON, Harry W. Polarization Reversal in Developing Countries. Papers and Proceedings of the Regional Science Association, v.45, 1980.

STHÖR, W. B. \& TAYLOR, D.R.F. (eds.). Development from Above or Below? The Dialectics of Planning in Developing Countries. John Wiley, 1981.

SUDENE. Desigualdades Regionais no Desenvolvimento Brasileiro. Recife, 1984, 4 vol.

WERNECK, R.L.F. Empresas Estatais e Política Macroeconômica. Rio de Janeiro, Campus, 1987. 